\title{
Psychometric Performance of Prosocial Tendencies Measure for Undergraduates in Guangdong Province
}

\author{
Yongmei Hou*, Zhongyi Zheng and Que Zheng \\ Department of Psychology, School of Humanity and Administration, Guangdong Medical University, \\ Dongguan 523808, Guangdong Province, China
}

\begin{abstract}
Objective: To analyze the psychometric performance of Prosocial Tendencies Measure (PTM) for undergraduates in Guangdong province. Methods: Stratified random sampling method was used to select 1109 undergraduates from 10 colleges in Guangdong province.PTM was used to investigate them. Cronbach's $\alpha$ coefficient and split-half reliability were used to analyze the internal consistency of the questionnaire.Convergent validity, discriminant validity and factor analysis were used to evaluate its structural validity. Celling and floor effect were used to analyze its sensitivity. Results: Cronbach's $\alpha$ coefficient of the total questionniar was 0.94 and cronbach's $\alpha$ coefficient of 6 dimensions were $0.82 \sim 0.87$, which met with the requirements of the group comparison. Spearman - Brown split-half coefficient of the total questionniar was 0.95 , and the split half reliability of 6 dimensions were $0.83 \sim 0.88$. The calibration success rate of convergent validity and discriminant validity of the 6 dimensions were all $100 \%$. One component obtained from 23 items which cumulative variance contribution rate was $82.31 \%$. The total score and scores of 6 dimensions were all positive skew distribution, with floor effect in 6 dimensions. Conclusions: The psychometric properties of PTM for undergraduates in Guangdong was valid and reliable.
\end{abstract}

Keywords: PTM, Prosocial Tendencies, Validity, Reliability, Undergraduates

\section{Introduction}

Prosocial behavior refers to a kind of behavior that the actor voluntarily brings benefits to the recipient (others or society), including helping others, cooperation, sharing, politeness and so on [1]. This kind of behavior usually needs to pay a certain cost or risk, but it is of great significance to individual development and social harmony. Previous studies have shown that prosocial behavior helps individuals maintain positive emotions [2-3], improve academic [4] and professional performance [5], create good interpersonal relationship [4], enhance self-esteem and self-confidence [6], cultivate psychological qualities such as innovation [7], empathy [8] and sense of responsibility [8], reduce behavior problems such

* Corresponding author: 2184456621@,qq.com 
as aggression [9], internet addiction [10], and promote social adaptation [11-12]. Due to the great significance of prosocial behavior, it is increasingly concerned by all sectors of society.

Prosocial Tendencies Measure (PTM) [13] was developed by American psychologists Carlo and Randall (2002) [13] and revised by Cong Wenjun into Chinese version [14]. It has concise items, clear structure and cross-cultural stability. Since the compilation, it has been more and more widely used. But what is the psychometric performance of PTM for college students? There is no relevant evidence.

Based on the above analysis, this study intends to explore the psychometric performance of PTM for college students in Guangdong Province.

\section{Object and method}

\subsection{Object}

\subsubsection{Sample Size Estimation}

The minimum sample size is calculated by $\mathrm{G}^{*}$ power 3 [15]. As PTM is used to evaluate the indicators related to mental health, and disease is one of the important indicators of mental health, we use the prevalence of mental illness of college students to calculate the sample size. Previous studies have shown that the prevalence of mental illness among college students is $9.0-27.7 \%$ [16-18], and the test effect value is medium level [16-18], that is, the $D$ value is $0.50-0.80$ [19]. In this study, we set the effect value $d=0.70$, the statistical test power of $1-\beta=0.80$, the type I error probability $\alpha=0.05$, and the minimum sample size is calculated as 678 . The minimum sample size is determined as 825 due to a $20 \%$ of possible follow-up loss rate.

\subsubsection{Sampling}

From March to April, 2019, a total of 1200 questionnaires were distributed to college students from freshmen to fifth year from Guangdong Pharmaceutical University, Guangdong Medical University, Guangdong Academy of Fine Arts, Xinghai Conservatory of Music, Jinan University, Guangdong University of Finance \& Economics, Guangdong University of Foreign Studies, Dongguan University of Technology, Guangdong University of Technology and Shenzhen University by stratified random sampling. 1109 valid questionnaires were collected, with an effective rate of $92.4 \%$. Among them, there were 536 males and 573 females; 243 in comprehensive colleges, 304 in science and engineering colleges, 145 in liberal arts colleges, 197 in medical colleges, 95 in finance and economics colleges, 74 in sports colleges and 50 in art colleges; 231 freshmen, 219 sophomores, 225 juniors, 230 seniors, 204 fifth year students; 745 from urban areas and 364 from rural areas.

\subsection{Tools}

\subsubsection{Prosocial Tendencies Measure, PTM}

It is compiled by Carlo and Randall (2002) [13], and revised by CONG Wenjun [14] into Chinese version. There are 23 questions, divided into six dimensions: "open prosocial behavior", "anonymous prosocial behavior", "altruistic prosocial behavior", "compliance prosocial behavior", "emotional prosocial behavior" and "emergent prosocial behavior". 
The Likert 5-point scoring method is used to score from 1 to 5 points corresponding to "not at all" to "completely yes". The higher the total score, the higher the degree of prosocial tendencies.

\subsubsection{Self-compiled Personal Information Questionnaire}

It includes 4 items, namely, gender, grade, origin, college.

\subsection{Collection and arrangement of data}

Before the investigation, the researchers who participated in the survey were trained uniformly, and the investigation process and evaluation standard were unified. The consistency test (kappa $=0.81 \sim 0.90$ ) meet the test requirements.

The questionnaires with scores of more than $50 \%$ of the items missing were eliminated. The missing values of the valid questionnaire were estimated and filled with the average. Two researchers independently input the same data using Epidata3.0 software and conduct a unified logic check to ensure the accuracy of the data.

\subsection{Statistical methods}

Data were exported from epidata3.0 to SPSS 20.0 for statistical analysis. First, the original score of the total scale and each dimension were calculated. The second step was to get the average score and standard deviation of the total scale and each dimension. In the third step, the floor and ceiling effect were evaluated, and then, cronbach's a coefficient and split half reliability were calculated. Finally, convergent validity, discriminant validity and principal component factor analysis were conducted.

\section{Results}

\subsection{The distribution of PTM scores}

The ceiling / floor effect is one of the psychological test effects, which refers to the phenomenon that when a test is too simple / complex, the scores of most subjects are close to or reach the upper / lower limit of scores, which makes the evaluation and prediction performance of the test decrease [15]. Table 1 shows that the total score of PTM and the scores of 6 dimensions all tend to be positively skewed distribution. Floor effects appear in all 6 dimensions, but there is no ceiling effect. 
Table 1. Descriptive Analysis of PTM ( $n=1109)$.

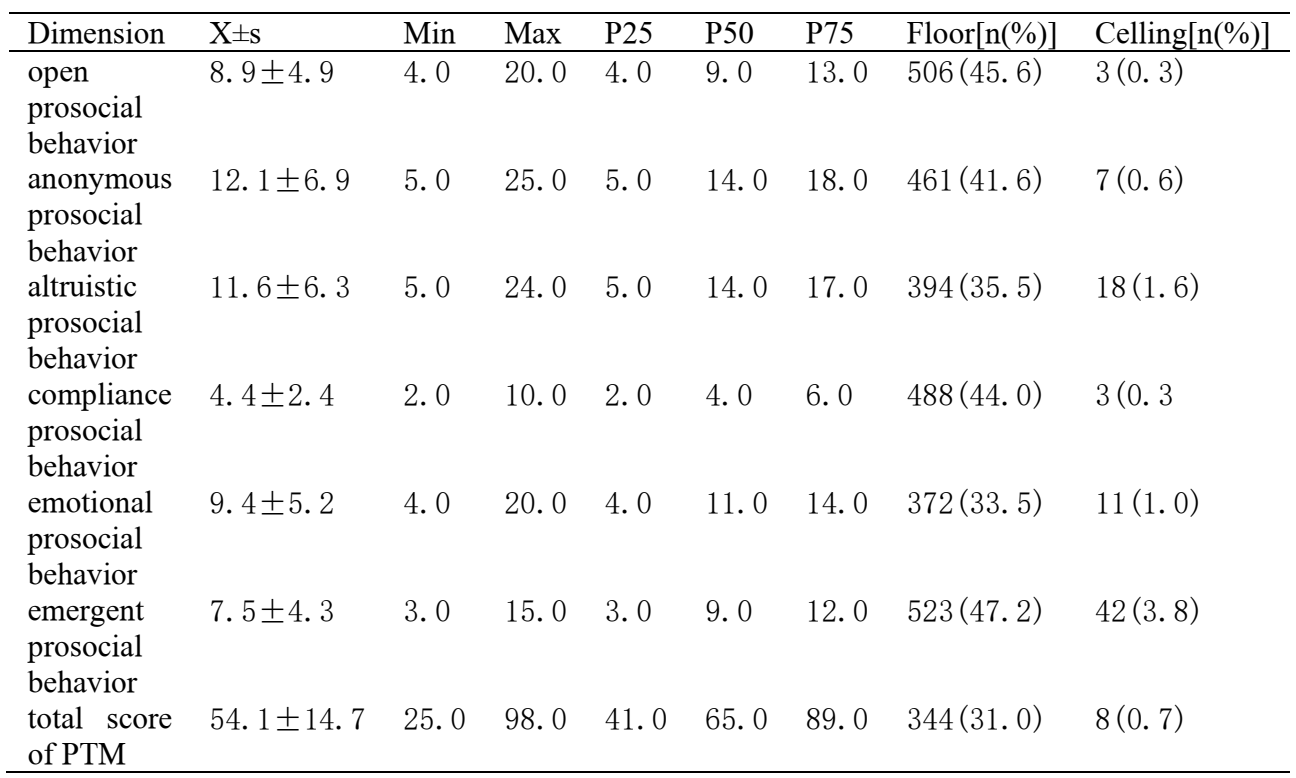

\subsection{Reliability analysis of PTM}

\subsubsection{Split half reliability}

The 23 items of PTM were divided into 12 and 13 items respectively, and the correlation coefficients of these two parts was 0.93. According to Sperman Brown formula, the split half reliability of the total scale was 0.95 . The correlation coefficients of the two halves of 6 dimensions were $0.79,0.83,0.81,0.78,0.82$ and 0.81 , and the split half reliability were $0.83,0.86,0.88,0.84,0.86$ and 0.85 , respectively.

\subsubsection{Internal consistency reliability}

Generally speaking, when Cronbach's a coefficient is greater than 0.7 , the internal consistency reliability is better. It can be seen from table 2 that the Cronbach's a coefficient of the total scale is 0.94 , and those of the 6 dimensions are $0.82 \sim 0.87$. There is a moderate pair wise correlation among the dimensions $(\mathrm{r}=0.01)$. 
Table 2. Cronbach'a Coefficients and Pair Wise Correlation Coefficients.

\begin{tabular}{|c|c|c|c|c|c|c|c|c|}
\hline Dimension & $\begin{array}{c}\text { Cronbach's } \\
\alpha\end{array}$ & 1 & 2 & 3 & 4 & 5 & 6 & 7 \\
\hline $\begin{array}{l}\text { 1.open prosocial } \\
\text { behavior }\end{array}$ & .85 & & & & & & & \\
\hline $\begin{array}{l}\text { 2.anonymous } \\
\text { prosocial } \\
\text { behavior }\end{array}$ & .87 & $.62 * *$ & & & & & & \\
\hline $\begin{array}{l}\text { 3. altruistic } \\
\text { prosocial } \\
\text { behavior }\end{array}$ & .84 & $.78 * *$ & $.68 * *$ & & & & & \\
\hline $\begin{array}{l}\text { 4.compliance } \\
\text { prosocial } \\
\text { behavior }\end{array}$ & .82 & $.63^{* *}$ & $.62 * *$ & $.65^{* *}$ & & & & \\
\hline $\begin{array}{l}\text { 5.emotional } \\
\text { prosocial } \\
\text { behavior }\end{array}$ & .85 & $.69^{* *}$ & $.67 * *$ & $.70^{* *}$ & $.64 * *$ & & & \\
\hline $\begin{array}{l}\text { 6.emergent } \\
\text { prosocial } \\
\text { behavior }\end{array}$ & .86 & $.66^{* *}$ & $.68^{* *}$ & $.69^{* *}$ & $.65^{* *}$ & $.70^{* *}$ & & \\
\hline $\begin{array}{l}\text { 7.total score of } \\
\text { PTM }\end{array}$ & .94 & $.70^{* *}$ & $.71 * *$ & $.73 * *$ & $.68 * *$ & $.73 * *$ & $.73^{* *}$ & \\
\hline
\end{tabular}

$* * \mathrm{P}<0.01$

\subsection{Validity analysis of PTM}

\subsubsection{Content validity}

The correlation coefficient $(\mathrm{R})$ between each item and its dimension is used to represent the convergent validity. Generally, when $\mathrm{R} \geqslant 0.4$, it can be considered that the convergent validity is better. Discriminant validity is expressed by the correlation coefficient between the item and other dimensions. If these correlation coefficients are lower than the correlation coefficient between the item and its dimension, the discriminant validity is better. The results show that the correlation coefficient between each item and its dimension was $>0.4$, which was higher than those correlation coefficients between the same item with other dimensions. The calibration success rates of convergent validity and discriminant validity were $100 \%$. See Table 3 . 
Table 3. Convergent validity and discriminant validity of PTM $(n=1109)$.

\begin{tabular}{|c|c|c|c|c|c|c|c|}
\hline \multirow[b]{2}{*}{ dimension } & \multirow[b]{2}{*}{$\begin{array}{l}\text { item } \\
\text { number }\end{array}$} & \multicolumn{3}{|c|}{ Convergent Vality } & \multicolumn{2}{|c|}{ Discriminant Vality } & \multirow[b]{2}{*}{ success rate } \\
\hline & & range of $R$ & success & $\begin{array}{l}\text { success } \\
\text { rate }\end{array}$ & range of $R$ & success & \\
\hline $\begin{array}{l}\text { open prosocial } \\
\text { behavior }\end{array}$ & 4 & $.653 \sim .721$ & $4 / 4$ & 100 & $.440 \sim .652$ & $20 / 20$ & 100 \\
\hline $\begin{array}{l}\text { anonymous } \\
\text { prosocial } \\
\text { behavior }\end{array}$ & 5 & $.689 \sim .726$ & $5 / 5$ & 100 & $.612 \sim .703$ & $25 / 25$ & 100 \\
\hline $\begin{array}{l}\text { altruistic } \\
\text { prosocial } \\
\text { behavior }\end{array}$ & 5 & $.600 \sim .795$ & $5 / 5$ & 100 & $.403 \sim .671$ & $25 / 25$ & 100 \\
\hline $\begin{array}{l}\text { compliance } \\
\text { prosocial } \\
\text { behavior }\end{array}$ & 2 & $.772 \sim .775$ & $2 / 2$ & 100 & $.614 \sim .703$ & $10 / 10$ & 100 \\
\hline $\begin{array}{l}\text { emotional } \\
\text { prosocial } \\
\text { behavior }\end{array}$ & 4 & $.669 \sim .706$ & $4 / 4$ & 100 & $574 \sim .673$ & $20 / 20$ & 100 \\
\hline $\begin{array}{l}\text { emergent } \\
\text { prosocial } \\
\text { behavior }\end{array}$ & 3 & $.709 \sim .720$ & $3 / 3$ & 100 & $.596 \sim .686$ & $15 / 15$ & 100 \\
\hline
\end{tabular}

\subsubsection{Construct validity}

As KMO value is 0.979, Bartlett's spherical test value is 43406. $96(\mathrm{df}=253), \mathrm{P}<0.001$. Therefore, the data is suitable for factor analysis. According to the eigenvalue value greater than 1 , one principal component is extracted. The factor load of each item is $0.57 \sim 0.71$, and the cumulative contribution rate is $82.31 \%$.

\section{Discussion}

We found that the psychometric performance of PTM was good, which was consistent with the results of previous literature [13,14,20-24], suggesting that PTM was suitable for college students in Guangdong.

First, the test of internal consistency reliability and split half reliability showed that PTM had good reliability. The internal consistency reliability of total scale and each dimension was above 0.82 ; the split half reliability of total scale and each dimension was above 0.83, which was consistent with the results of previous studies [13-14,20-24]. It suggested the split half and internal consistency reliability were good.

Second, there was a high correlation between each dimension and the total score; factor analysis made on the scores of 23 items showed that one principal component was extracted, with the cumulative contribution rate of $82.31 \%$, suggesting that the structural validity of PTM was good. On the other hand, structure extracted from this principal component analysis was not consistent with the 6 dimensional theoretical conception of the original scale [13], which may be caused by different cultural backgrounds. The prosocial behaviors included 6 situations described in the original scale [13]. In essence, they are restricted by personality (especially values). Therefore, there is a significant positive pair wise correlation between the scores of 6 dimensions of the original scale and only one principal component can be extracted.

Third, the scores in all dimensions were positively skewed. Floor effect appeared in 6 dimensions, but there was no ceiling effect. It was consistent with the results of previous literature [14], suggesting that there were still some college students $(33.5-45.6 \%)$ who 
were not accustomed to prosocial behavior. Most of them were close to or reach the lower limit of the scores in 6 dimensions at the same time, so the sensitivity was affected to a certain extent.

\section{References}

1. N Eisenberg and P A Miller. The relation of empathy to prosocial and related behaviors, Psychological Bulletin, 101(1), 91-119, (1987)

2. F Sun, L Z Lin, M X Dai, M F Luo, G H Cuo, W H Yang, J Jing. Autistic traits, empathy and theory of mind among college Students with different level of Prosocial behaviors, Journal of Sun Yat Sen University (Medical Sciences Edition). 38(6), 938943 (2017)

3. Y G Li, D Luo. Research on the positive emotion experience of cooperative prosocial behavior in college students, Journal of Chongqing University (Social Science Edition). 19(4), 177-182 (2013)

4. M F Wang, H C Chen. The relationship between adolescents' academic achievement, prosocial behavior and peer acceptance and rejection, Journal of Psychological Science. 26(6), 1130-1131 (2003)

5. Z Zheng, M Jia. Relationships between daily affect and customer-oriented service behavior at work: The moderating role of prosocial motivation, Forcasting. 32(6), 8-14, (2013)

6. A Zuffianò, G Alessandri, B Paula, L Kanacri, C Pastorelli, M Milioni, R Ceravolo, M G Caprara, G V Caprara. The relation between prosociality and self-esteem from middle adolescence to young adulthood, Personality and Individual Differences, 63 , 24-29 (2014)

7. X Y Luan, C Chen. The influence of prosocial motivation on innovation behavior: Taking transposition thinking as intermediary variable, Operation and management, $\mathbf{5}$, 20-22 (2020)

8. Q Y Li, L S Wang, Y Tian. A study on the correlation between empathy, social responsibility and prosocial behavior among College Students, Modern communication, 13, 107-109 (2018).

9. Y H Liang, M H Z Hou. The influence of prosocial tendencies on Implicit Aggression - the Enlightenment of social learning theory on prosocial behavior of College Students under different levels of violence, Theory Research, 21(11) 59-61 (2014)

10. M Q Mo, Y H Yang, X Z Xu. Influence of pro - social motivation on internet addiction: Chain mediating effect of basic psychology needs, Journal of Shaoyang University(Social Science Edition), 22(5) 114-120 (2015)

11. L K Zheng, X Liu. The college students' prosocial behavior: based on structural equation model of the psychological crisis' intervention, Statistics \& Information Forum, 28(5), 100-106(2013)

12. P Jin, G M Sun, Q M Chen. Research on the relationship between prosocial behavior and adaptability of college students, Economic Herald, 23, 76-77, (2013)

13. G Carlo, B A. Randall. The development of a measure of prosocial behaviors for late adolescents, J Youth Adolesc. 31(1), 31-44 (2002)

14. W J Cong. Research on the types of prosocial behavior of college students, Ma. D. Thesis, Nanjing Normal University (2008)

15. J Cohen. Statistical power analysis, Curr Direct Psychol Sci. 1(3), 98-101 (1992) 
16. Y Hu. A study on the limitations of SCL-90 in mental health survey of freshmen, Journal of Changchun University. 22(4), 444-447 (2012).

17. Y Teng. The application of cluster analysis and discriminant analysis in the results of SCL-90 among test college students, Chinese Journal of Social Medicine. 34(5), 460462 (2017)

18. L Y Shi, J P Xu, ZHOU Lang, WU Xiujuan, ZHAO Huashuo, GENG Debao, ZHANG Xunbao. Reference value, reliability and validity of SCL-90 in college students, Chin J Sch Health. 34(2), 223-224 (2013)

19. H C Zhang, J P XU Jianping. Modern psychology and educational statistics, Beijing Normal University Publishing Group, Beijing, 2012.

20. C Zhang, Y J Zhang, Q Y Wang, L J Hao. Research on the relationship among posttraumatic growth, gratitude and prosocial behavior, Journal of Logistics University of PAP (Medical Sciences), 27(6), 489-494 (2018)

21. W Yao, L S Wang, Hao Li. The effect of college students' shame on prosocial behavior, psychology: Techniques and Applications, 7(1) 34-38 (2019)

22. Y F Lei, D X Guan, L Chen. Relationship between parental rearing, empathy and early prosocial behavior of adolescents, Youth and Adolescent Studies, 2, 59-64 (2020)

23. T C Li. The influence of gratitude on prosocial tendency of college students, Journal of Campus Life \& Mental Health, 18(3), 237-240 (2020)

24. Lu Li, B J Ye, L Y Ni, Q Yang. Family cohesion on prosocial behavior in college Students: Moderated mediating effect, Chinese Journal of Clinical Psychology, 28(1), 178-180 (2020) 